repaired in BRCA2-deficient cells. Otherwise, during DNA replication, these breaks can evolve into deadly double-strand breaks. This requirement led to a proposal ${ }^{3,4}$ of a new therapeutic strategy for HR-deficient tumour cells, including $B R C A 2^{-/-}$cells. Base-excision repair, another DNA-repair pathway, is involved in repairing single-strand DNA breaks. Among the proteins that are essential in base-excision repair is poly(ADP-ribose) polymerase (PARP). The idea was that an inhibitor of PARP would kill HR-deficient cells but not their normal counterparts. This is because HR-deficient cells, including those that are $B R C A 2^{-/-}$, cannot rely on HR to repair the double-strand breaks that evolve from single-strand breaks when base-excision repair is inhibited. The results of tissue-culture experiments supported this hypothesis, and clinical trials of potent PARP inhibitors are afoot.

Ashworth's and Taniguchi's groups ${ }^{1,2}$ now describe the results of analysing drug-resistant BRCA2-deficient tumour cells. The story is the same in clones derived from cultured $B R C A 2^{-/-}$tumour cells that are resistant to PARP inhibitors or Pt, and in Pt-resistant $B R C A 2^{-/-}$ovarian cancers from the clinic. Tumour cells carrying a known, diseaseinducing mutation of the BRCA2 gene that produces a shortened, defective protein incur a second mutation that results in the production of a functionally normal protein. More specifically, the consequences of the original ('frameshift') mutation are largely negated by a second mutation that re-establishes the normal $B R C A 2$ sequence. Consequently, unlike their predecessors, the revertant cells are HR 'competent' - that is, they can perform HR. As a result, they are resistant to the drug to which they were once sensitive. Transfer of the doublemutant, resistance-associated $B R C A 2$ gene variant to a $B R C A 2$-deficient, $H R$-defective cell line confers both HR competence and drug resistance. Thus, in patient tumour cells and cell lines alike, HR competence spells resistance to both PARP inhibitors and Pt. This result shows unequivocally that these drugs require faulty HR for antitumour activity in this setting.

The results have clinical implications for situations in which drug resistance has developed. Further treatment with chemotherapy that creates DNA crosslinks, or inhibits baseexcision repair, is likely to be less effective in HR-competent cells than in HR-incompetent cells. Moreover, in HR-incompetent cells that have acquired drug resistance through other mechanisms (such as the action of cellular pumps that eject the drug), the use of treatments different from those to which resistance has arisen is an obvious course - a different form of DNA-crosslinking chemotherapy, for example, or a different class of agents that inhibit base-excision repair.

There is even a potential biomarker that could, in principle, be used to assess HR competence in tumour cells, and thus instruct therapeutic decisions. This biomarker is Rad51, a protein that catalyses a key step in HR. A sign of HR competence is the appearance of Rad51-containing foci in the nuclei of cells after double-strand breaks have occurred. Many HR-incompetent cells cannot produce these foci, whereas most HR-competent cells should contain them. When present, they can be readily visualized by immunofluorescence. Isolation of viable tumour cells by direct biopsy of a tumour mass, or even from the patient's bloodstream, as recently suggested ${ }^{5}$, might make it possible to analyse post-damage Rad51 foci and help to clarify the nature of a patient's drug resistance.

The new findings ${ }^{1,2}$ raise other considerations. Neither Pt nor PARP inhibitors interact directly with the mutant protein (BRCA2) whose functional reactivation leads to resistance. So, drug-design strategies that target anticipated resistance mutations, and that have been useful in other tumour-cell settings, will not apply in this one. Further, we may be seeing here the beginning of a new challenge in the growing discipline of pharmacogenomics, which deals with the influence of genetics on drug responsiveness. This is because different $B R C A 2$ mutations probably vary in their ability to undergo reversion by the kinds of mechanisms described by the authors ${ }^{1,2}$. One wonders, for example, whether patients with substantial BRCA2 deletions have more durable clinical responses to $\mathrm{Pt}$ than patients with mutations that are more readily amenable to reversion, such as the ones studied in these reports.

Finally, there are broader implications. Many patients with ovarian cancer who have normal $B R C A 2$ genes respond to $\mathrm{Pt}$. So it could be that their tumour cells are inherently less HR

competent than the normal cells from which they are derived. Second, until now it has remained a possibility that continued BRCA2 deficiency is required for maintaining various features of cancer. This is especially so given recent evidence that the absence of BRCA1, a tumour-suppressor protein involved in many of the same processes as BRCA2, helps a tumour to recruit a blood-vessel supply, which is essential for tumour survival ${ }^{6}$. However, a tumour analysed by the Taniguchi group ${ }^{2}$ contained a direct reversion of the HR-deficient $B R C A 2$ mutation after Pt therapy. This resulted in a completely normal BRCA 2 coding unit and therefore restoration of a normal BRCA2 protein, but no regression of the tumour. These findings imply that a temporary loss of BRCA2 function is enough to establish the cancer, which is consistent with the view that BRCA2 loss results in a substantially increased rate of DNA damage that, in turn, triggers cancer. In other words, the results reinforce the notion that $B R C A 2$ is a caretaker tumour-suppressor gene (inactivation of which allows mutation in other cancer-causing genes), and not a gatekeeper tumour-suppressor gene (which directly controls tumour growth $)^{7}$.

David M. Livingston and Daniel P. Silver are at the Dana-Farber Cancer Institute, Harvard Medical

School, 44 Binney Street, Boston, Massachusetts 02115, USA.

e-mails: david_livingston@dfci.harvard.edu; daniel_silver@dfci.harvard.edu

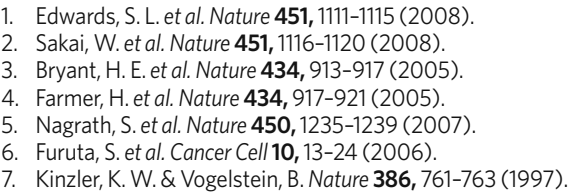

\title{
ENVIRONMENTAL ECONOMICS
}

\section{To the rich man the spoils}

\author{
R. Kerry Turner and Brendan Fisher
}

\section{Global economic growth during the past century has lifted many into lives of unprecedented luxury. The cost has been the degradation of vital ecosystems - a cost borne disproportionately by the world's poor.}

Through our rapacious exploitation, ecosystems and the benefits they bring to us are disappearing at an unprecedented and alarming rate. Qualitative evidence suggests that the rich world is profiting from this process, whereas poorer countries are bearing the brunt of the resulting environmental degradation. Srinivasan et al. ${ }^{1}$, writing in Proceedings of the National Academy of Sciences, provide a quantitative basis for that claim, calculating the distribution of costs and benefits over a range of indicators of ecosystem change. The results might, in an ideal world, lead to a radical reassessment of who is in debt to whom.
Measured in terms of gross domestic product (GDP), the size of the world's economy has doubled almost three times since 1950. But the proposition that aggregate economic growth alone is the most important and powerful force for human progress and poverty reduction has increasingly been questioned ${ }^{2,3}$. Economic growth fuelled by international trade relies on the consumption of heavily advertised and marketed goods and services. Poorer people and the natural world, marginalized by the market economy, lose out.

Besides basic economic needs, a high quality of human life must include satisfactory human 
relationships, communities, freedoms and opportunities $^{4,5}$. Well-functioning ecosystems are even more fundamental. The buzz-word is 'ecosystem services': the favours such as food and fuel; protection from storms, disease and solar radiation; regulation of water and climate; creation of soils; and inspiration for art, literature, religion and culture that the natural world bestows on us. Current economic models undervalue this provision, because many ecosystem services are 'public goods', historically provided for free. This leaves them prone to overexploitation, a trend exacerbated by global population growth: 15 of the 24 ecosystem services identified in the seminal Millennium Ecosystem Assessment initiated by the United Nations in 2001 were found to be in decline at the global scale ${ }^{6}$.

The current political focus on climate change has brought this pressure on our ecological support systems into sharper relief. Sustaining ecosystem processes is all the more difficult because many change abruptly and nonlinearly when pressed beyond a certain threshold. Qualitative or context- and casespecific evidence indicates that poorer countries bear most of this pressure ${ }^{7}$. An example is the widespread conversion of tropical mangrove forests to shrimp aquaculture. These farms supply Europe and North America with cheap shrimp, but nearby residents must pay the costs: the loss of the storm regulation, fish nurseries, and fuel and fibre sources that the mangrove forests provided ${ }^{8}$.

This type of unequal exchange has been termed an 'ecological debt' owed by rich countries to the poor ${ }^{7}$. As raw materials whether they be shrimp, palm oil, or crude oil and gas - become scarcer, and exploitation of them advances into new territories, this debt will probably increase. The prices at which exports are sold do not include compensation for the goods' local - or sometimes global environmental costs. That problem is exacerbated by rich countries' disproportionate use of environmental sinks, such as the atmosphere, to take up their higher carbon emissions.

Srinivasan et al. ${ }^{1}$ present for the first time a global-scale quantitative analysis of the distribution of major environmental costs across nations in three income groups: low (representing 32\% of the world's population), middle (50\%) and high (18\%). The timescale of the study is 1961-2000, and it covers six categories of environmental change: climate change; stratospheric ozone depletion; agricultural intensification and expansion; deforestation; overfishing; and mangrove conversion. In the case of climate change, the authors calculate that nations in the low, middle and high income groups were responsible for $13 \%, 45 \%$ and $42 \%$ of greenhouse-gas emissions, respectively. The resulting climate damages were estimated to be distributed $29 \%, 45 \%$ and $25 \%$. The same pattern of cost transfer to the poorest nations is observed for ozone depletion, overfishing and aquaculture. In the case of agricultural change

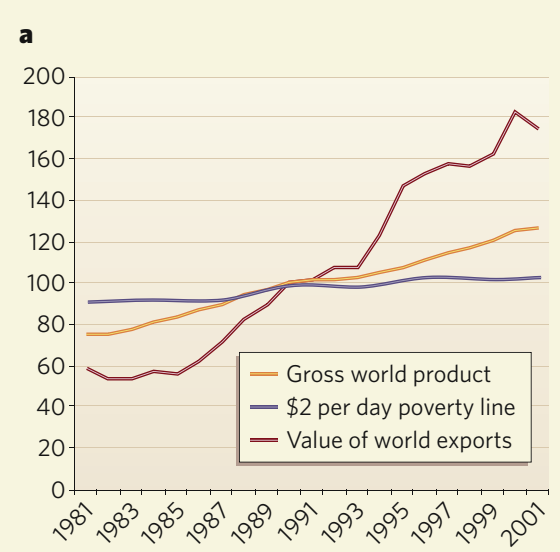

\section{b}

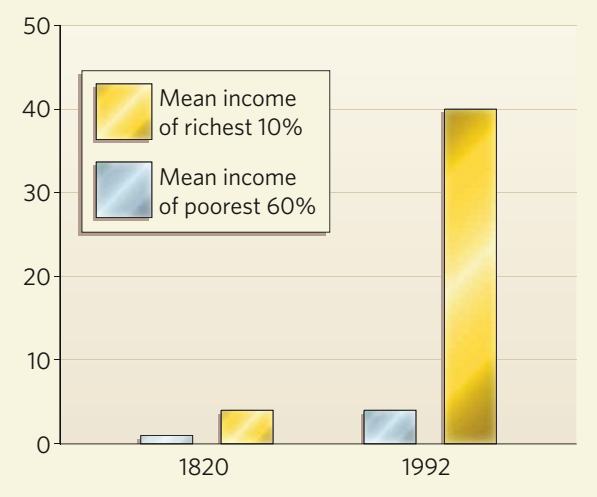

Figure 1 Inequality in economic growth. a, Although gross world product and the value of exports throughout the world rose steadily during the period 1981-2001 (values relative to 1990=100), the number living below the US\$2 per day poverty line has increased slightly ${ }^{10} \cdot b$, Whereas in 1820 the difference between the mean incomes of the poorest $60 \%$ of countries and of the richest $10 \%$ was fourfold, by 1992 the disparity was tenfold (value of mean income of poorest countries in $1820=1)^{9}$.

and deforestation, the authors find that arguably the costs were largely generated and borne within nations.

When the figures for the six categories are aggregated and adjusted for different currency purchasing power, the low-income group of nations bears $20 \%$ of the total costs, the middle-income group $60 \%$ and the high-income group $20 \%$. Taking into account equity weighting (the fact that a unit of income is not the same to a poor as to a rich person, making costs a heavier burden to shoulder) the percentages are $45 \%, 52 \%$ and $3 \%$. A significant proportion of the cost burden of the low-income group is caused by the activities of the other groups: looking at climate-change damage alone, rich countries might already have imposed costs on poor countries greater than the poor countries' existing foreign debt. The people bearing these costs include the one billion or so who already lack daily access to safe drinking water, electricity, secure food supplies and basic education.

Several caveats are needed to put these striking results into context. First, any study is only as good as the available data. Globally robust data sets on environmental externalities are incomplete, and therefore the results are indicative, not absolute. Some significant environmental changes have been omitted: the destruction of coral reefs, the dispersal of persistent pollutants and the costs of biodiversity loss. The authors are up-front about these limitations. But they justly suggest that the omissions indicate that their estimates of ecological debts are conservative.

Furthermore, the study does not look at the benefits of increased trade to material wealth and human health. But it is unlikely that this would change the balance of the results: the available, albeit partial, evidence indicates that, despite some gains by poorer countries through the liberalization of trade and finance, the number of people living in poverty has increased or stayed the same during the past 25 years, and the gains of economic globalization have been heavily skewed towards wealthy nations ${ }^{2}$ (Fig. 1). One of the most detailed studies on global inequality concludes ${ }^{9}$ that income divergence between rich and poor nations has "at best ... decelerated after 1950, but [has] not reversed". Large areas of Central and South America, and almost all of sub-Saharan Africa, have been left behind.

Srinivasan and colleagues' work ${ }^{1}$ should raise the scientific profile of issues vital to human well-being, including research into ecosystem services and the effects of large-scale ecosystem conversion, and how such changes both create and alleviate poverty. We must better understand the complex interactions between our economic, social and ecological systems, and the biological diversity that supports them. Scientists and society as a whole need to ask of our current economic paradigms in an era of globalization: why do they produce such inequities; who pays the costs; and are they ecologically and socially sustainable?

R. Kerry Turner and Brendan Fisher are at the Centre for Social and Economic Research on the Global Environment (CSERGE), School of Environmental Sciences, University of East Anglia, Norwich, Norfolk NR4 7TJ, UK.

1. Srinivasan, U. T. et al. Proc. Natl Acad. Sci. USA doi:10.1073/ pnas.0709562104 (2008).

2. Stiglitz, J. E. Globalization and Its Discontents (Norton, New York, 2003).

3. Wade, R. H. World Dev. 32, 567-589 (2004)

4. Sen, A. Development as Freedom (Anchor, New York, 1999).

5. Layard, R. Happiness: Lessons from a New Science (Allen Lane, London, 2005).

6. Millennium Ecosystem Assessment, Ecosystems and Human Well-Being: Synthesis (Island, Washington DC, 2005).

7. Martinez-Alier, J. The Environmentalism of the Poor (Oxford Univ. Press, New Delhi, 2005)

8. Sathirathai, S. \& Barbier, E. B. Contemp. Econ. Pol. 19, 109-122 (2001).

9. Bourguignon, F. \& Morrisson, C. Am. Econ. Rev. 92, 727-744 (2002).

10. World Development Indicators 2007 www.worldbank. org/data (2007). 